\title{
LA LECTURA DE TEXTOS LITERARIOS EN EL COLEGIO ¿PORQUÉ NO LEEN LOS ESTUDIANTES?
}

\author{
Isabel Gallardo Álvarez \\ Profesora de la Escuela de Formación Docente.
}

Recibido 31-III-2006

Aceptado 25-IV-2006

\begin{abstract}
Resumen: ¿Porqué no leen los estudiantes de secundaria los textos literarios que les piden los docentes? Este artículo intenta contestar la pregunta refiriéndose a algunos de los aspectos que pueden provocar esta falta de gusto por la lectura. Uno de ellos se refiere a los cambios culturales ocurridos en las sociedades en los últimos tiempos, otro es la falta de ejemplo en el hogar, con padres que no son lectores y el último es el tipo de textos que se escogen en el colegio como obligatorios para la lectura. Estos, más la forma de enseñarlos en los colegios, son algunos de los factores que no están ayudando a que el estudiante adolescente se acerque con placer al texto literario.
\end{abstract}

Palabras clave: Lectura, placer, saberes, texto literario, habilidades lectoras, lecturas obligatorias, docente de Español.

Abstract: Why do secondary school students not read the literary texts that teachers ask them to read? This article intends to answer this question presenting some of the factors that might cause a lack of interest in reading. One of these factors are the cultural changes that have taken place in societies around the world. A second factor analyzed is the lack of role models at home. That is, students whose parents are not readers either. The third factor is the types of reading texts chosen by schools as mandatory texts. The study concludes that neither of these factors encourage teenage students' pleaure to read literary texts.

Key words: Reading, reading for pleasure, knowledge, literary texts, reading skills, mandatory texts, Spanish teachers.
Algunas profesoras y también profesores, no solo de educación secundaria sino también universitarios, se han preguntado a menudo, por los factores que hacen que los estudiantes no lean, o si lo hacen su comprensión sea poca o nula.

Ante esta realidad surge la pregunta ¿cuáles son los elementos que llevan al éxito de la lectura? La experiencia en las aulas ha sido más bien desalentadora, pues aunque muchos docentes se han preocupado por incentivar el acto de la lectura, parece que no han encontrado aún las fórmulas que proporcionen el éxito de la lectura en los adolescentes. Es por estas reflexiones que surgió la necesidad de explicarse primero el porqué los adolescentes actuales no leen y una vez conocida esta situación, es posible pensar actividades que puedan llevar al acercamiento del estudiante al texto mediante la lectura.

Para nadie es un secreto que los muchachos de hoy no leen. Los lamentos por la escasez de lectores en las aulas se escuchan entre los profesores de Español tanto de Primaria como de Secundaria y también entre los docentes universitarios. Por más que el maestro lo intente, por más que motive y "publicite" el texto literario, el estudiante, la mayoría de las veces, no se quiere acercar a él. 
Pareciera que no lo hacen por la aversión que han desarrollado hacia la lectura. Esta se hace patente no más se acercan al texto, algunos incluso lo hacen con buena voluntad, pero en el primer capítulo, o lo que es peor, después de las tres primeras páginas, se desaniman, se aburren y no se sienten capaces de proseguir su labor. Y de ahí no pasan. Después de fracasar en la lectura del texto su esfuerzo se centra en buscar un resumen de la obra literaria asignada como lectura, que como bien se sabe, están disponibles en cualquier lugar, sobre todo en distintos sitios Internet ${ }^{1}$. Leen el resumen y así sienten que cumplen con su tarea.

No hay que ser ingenuo, no es que estos jóvenes no tengan paciencia para pasar sentados mucho tiempo dedicados a una sola labor o que carezcan del poder de la concentración para leer un texto impreso, pues cualquier mamá o papá podrá certificar que este mismo muchacho, que no puede siquiera leer tres páginas seguidas, pasa concentradísimo frente a la computadora chateando con sus amigos o divirtiéndose con los juegos virtuales por largas horas.

Los jóvenes de hoy poseen la capacidad de concentración para insistir durante horas en la resolución de uno de esos juegos virtuales o la paciencia enorme para ver tres películas de Hollywood seguidas sin pestañear siquiera.

Entonces, ¿por qué no leen? Tienen capacidad de concentración, son pacientes, empeñosos, resuelven problemas en la computadora que los adultos de hoy, educados en la época de las máquinas de escribir no podemos, pero aún así, tres páginas de Marianela o media de La Vorágine, los vencen con rapidez.

\section{Nuevos tiempos, nuevas lecturas}

Para enfocar este problema de la falta de gusto por la lectura por parte de los adolescentes, hay que recordar, en primer lugar que los tiempos han cambiado, y las urgencias culturales de hoy difieren mucho a las de nuestros padres o abuelos.

Dice Jesús Martín-Barbero (1993), refiriéndose a esta época, que estamos ante el

"desplazamiento de las demarcaciones y las fronteras entre razón e imaginación, ciencia y arte, naturaleza y artificio, la hibridación cultural entre tradición y modernidad, entre lo culto, lo popular y lo masivo" [Martín-Barbero. 1993. 19].

Son otros tiempos, hay otras urgencias, otros intereses, otras formas de vivir el mundo. Para los jóvenes actuales lo importante es jugar "play station" y resolver el nuevo juego de la semana, ver la última producción cinematográfica en "DVD", navegar por Internet y relacionarse virtualmente con conocidos y desconocidos; lo masivo, lo digital, lo virtual son los elementos culturales que dominan la vida pública y privada en la que se desenvuelve este adolescente, quien se encuentra perplejo ante el texto literario escrito y presentado en la forma tradicional de libro. Porque no hay que olvidar que los juegos virtuales, las películas, el conversar con otros virtualmente son también textos, textos que necesitan de códigos específicos para ser interpretados.

Una obra literaria es también un texto, que a su vez requiere del manejo de un código para ser comprendido, un código que nuestros antepasados dominaban a la perfección, pero que pareciera que en estos nuevos tiempos ha sido desplazado para imponer otros nuevos que son dominados por los adolescentes, nacidos en la era de la Internet.

Los jóvenes están viviendo en una nueva era, en un futuro diferente al conocido por sus padres, tal como lo señaló Margaret Mead, citada por Jesús MartínBarbero, al decir que es

"Un futuro que sólo balbucean los relatos de cienciaficción en los que los jóvenes encuentran narrada su experiencia de habitantes de un mundo cuya compleja heterogeneidad no se deja decir en las secuencias 
lineales que dictaba la palabra impresa, y que remite entonces a un aprendizaje fundado menos en la dependencia de los adultos que en la propia exploración que los habitantes del nuevo mundo tecno-cultural hacen de la imagen y la sonoridad, del tacto y la velocidad. (Martín-Barbero. 2002. P. 2).

Esta es una generación a la que le ha tocado una época nueva, una época que hasta hace poco solo se soñaba en los libros de ciencia-ficción. Una de sus características es que no se rige por la palabra impresa, y por ende ni por los libros, ni por la escritura. Es una generación visual, auditiva, de acción y movimiento. Sus lecturas son de acción, se oyen y casi se sienten. Los textos a los que se acercan son diferentes a los impresos, son textos virtuales, televisivos, musicales, son textos que requieren nuevas habilidades para interpretarlos y disfrutarlos. Habilidades que los jóvenes han estado desarrollando desde su nacimiento, cuando la televisión fue la primera en relatarles una historia.

Ello se apoya con las palabras del estudioso chileno Mauricio Ostria (2005) quien afirma:

"No sólo las formas exteriores de la vida y la convivencia social se modifican, sino también las normas valorativas, el horizonte del conocimiento, las conductas, los criterios de acción, las perspectivas, etc." (Ostria, 2005. P. 1).

El libro, el objeto material ya no significa lo que significaba en tiempos pasados, ahora no es ni común ni importante, son otros los objetos culturales que han adquirido relevancia, el juego virtual, la conexión rápida de Internet o el cine en el "home teather" del hogar.

Eso sí, a pesar de estos cambios culturales, de las nuevas opciones tecnológicas, de las nuevas conductas y saberes, hay que recordarle a estos adolescentes que la lectura continúa vigente y es un acto que no debe descuidarse y tiene que cultivarse junto con los nuevos saberes, porque la literatura, la lectura es un instrumento de conocimiento, que promueve la criticidad y diversión. Por eso se insiste en su enseñanza, y también en la lectura de aquellos textos que la sociedad y la historia han clasificado como literarios.

\section{¿Por qué no leen los estudiantes?}

El problema que entraña la falta de acercamiento del estudiante a la lectura, como ya se dijo, no es nuevo. Hay preocupación por este fenómeno, pues se sabe que el leer, el comprender e interpretar un texto es una de las formas de estar en el mundo, de entenderlo y transformarlo.

Un acercamiento al problema se puede encontrar en las palabras de Mauricio Ostria cuando afirma:

En este marco de cambios culturales profundos cuyo horizonte no alcanzamos a percibir del todo, debe situarse lo que se ha llamado la crisis del libro y la lectura y, por ende, de la práctica literaria, entendida como el circuito comunicativo de escritura-lectura. A nuestro juicio, se trata de la crisis de ciertas formas tradicionales de entender y fomentar la lectura de textos literarios y, no, necesariamente, de una crisis de la lectura, en general (Ostria. 2005. P. 2).

Para este autor no tanto se presenta una crisis en la lectura, sino más bien el problema se encuentra en la forma de acercarse a la lectura. Considera que el acercamiento tradicional que se está empleando está obviando esos nuevos saberes y habilidades que poseen actualmente los adolescentes.

El camino que se ha de seguir, en el colegio y por los profesores encargados es buscar la forma para que los jóvenes se acerquen a estos textos que pareciera les disgustan tanto. Les disgusta sobre todo porque no saben decodificar el texto impreso. Sus habilidades de decodificación, como se dijo antes, se han desarrollado en otros ámbitos, diferentes al texto escrito.

Con respecto a la importancia de leer literatura, el académico de la lengua mejicano, Felipe Garrido, reflexiona

\footnotetext{
“...la literatura explora la vida y esa es una materia
} que todos cursamos" (Garrido, 2005). 
La literatura es vida, es una parte de la vida, de lo que somos, de lo que el ser humano piensa, siente y llora. Pero para que el adolescente comprenda la importancia de la lectura de literatura debe ensenársele desde una óptica diferente, desde la óptica de los nuevos tiempos, porque el disgusto por la lectura obedece a distintas razones, y no solo las provenientes del cambio cultural.

Otra de las causas por las que el adolescente no lee puede originarse en el hogar, en la forma como se educan los niños actualmente, esta crianza, generalmente está exenta del acto de la lectura.

Los jóvenes que hoy cursan secundaria, crecieron arrullados por los medios audiovisuales. Recordemos que actualmente, en muchos hogares, la lectura del cuento antes de ir a la cama ha sido sustituida por un programa de televisión, esto los arrulla, los duerme y no la voz de algún familiar leyéndole un cuento y mostrándole las imágenes que lo acompañan.

La diversión de estos jóvenes, en sus primeros años de vida, no son los cuentos de la abuela, y mucho menos las conversaciones de sobremesa sobre lo real y lo imaginario o la lectura, en solitario, a la luz de la lámpara en la intimidad de su cama. Ahora es viendo televisión, jugando "play station" o curioseando en la computadora. Vuelve a intervenir Ostria al decir:

"Frente a una cultura en que las fuentes de información, las formas de conocimiento y los medios de lectura se multiplican y en que, consiguientemente, el libro deja de ser el centro" (Ostria. 2005. P. 2).

La lectura no se encuentra entre sus intereses, ni siquiera entre las actividades que desarrolla con sus progenitores. Es más, muchas veces los mismos adultos no leen, ni siquiera hojean el periódico por la mañana.

Actualmente el libro pareciera no jugar ningún papel dentro de la vida familiar. No hay una cultura familiar de la lectura, y si en casa no se lee ¿cómo un niño va a aprender algo que no conoce? Conoce otras formas de lectura que si practica y que ya se mencionaron.

Otra razón por la que el joven no lee y aunado a este desconocimiento de la cultura de la lectura en el hogar, y a su falta de práctica en la decodificación de códigos impresos, aparece en la educación formal, bajo la amenaza de una mala nota en una prueba si no leen el libro impuesto por la profesora, que ha su vez ha sido impuesto por el Ministerio de Educación Pública.

Se ha hablado mucho de la lectura como obligación versus la lectura como diversión, y aquí cabe hacerse una pregunta, ¿porqué tenemos que obligar a leer a los jóvenes, textos escogidos por expertos en literatura pero no en adolescentes, con la amenaza de un examen y una calificación?

Dice Daniel Penac (1992) que el verbo leer no admite imperativos. No se le puede ordenar a un joven que lea como no se le puede ordenar que ame o que sueñe. La lectura, siguiendo a Penac, debe ser un acto de placer y no tiene que estar signado por el temor, temor a una nota, temor a perder un curso, temor a una amonestación de parte de los padres o maestros.

Una bibliotecaria de Guadalajara (México) opina acerca de la obligación de la lectura:

"A mí, como a Penac, no me gusta el imperativo de leer, y no creo que se deba examinar a los lectores haciéndoles preguntas retorcidas para comprobar que han leído un libro. En los colegios se abusa de este procedimiento, y algunas editoriales siguen la corriente engordando los libros con espacios para contestaciones y resúmenes" (Calvo. 2005).

Si se recuerda lo que se acaba de hablar, sobre la falta de cultura de la lectura, el interés por otros medios de diversión y esparcimiento y además la poca relación con los libros que tiene el estudiante en la escuela primaria, se puede entender aún más el disgusto o temor, como sostiene Penac, del joven al acercarse a un texto literario de forma obligada.

Sobre este mismo tema Borges opina que "...la idea de la lectura obligatoria es 
una idea absurda: tanto valdría hablar de felicidad obligatoria" (Borges: 1998.107)

Para autores como los antes citados, la idea de leer por obligación es absurda y pareciera que esta obligación podría alejar aún más al joven de los textos. Recordemos que la etapa de crecimiento en que se encuentra el estudiante de colegio es la adolescencia, y en esa etapa se caracterizan por rechazar la figura del adulto, como figura de autoridad. Por eso, la imposición de un libro de literatura para leer, en un cierto tiempo, los aleja aún más del acto de la lectura y de descubrir el placer que esta puede darles.

Además, no solo se les obliga a leer determinados textos, sino que encima se les amenaza con pruebas de comprobación de lectura, a veces llenas de "retorcidas preguntas", que les hacen afirmarse aún más en su disgusto por el texto.
A veces pareciera que no solo rechazan al texto mismo, sino que también lo asocian a pruebas, calificaciones y promoción de nivel. Todo ello le hace ver al texto literario como algo lejano y que no proporciona ni placer ni diversión.

\section{¿Qué se lee en las aulas?}

Otro punto que se hace necesario revisar, para tratar de encontrar la razón por la que los estudiantes rechazan la lectura de los textos literarios asignados, es el carácter de obligatoriedad que poseen estos libros y la calificación que obtendrán en una prueba que demuestre la lectura que hicieron.

Actualmente, hasta la próxima reforma del Plan de Estudios, en sétimo y octavo año de la Educación General Básica se leen las siguientes obras literarias:

\begin{tabular}{|c|c|c|}
\hline Novela & Cuento & Ensayo/Crónica \\
\hline & Sétimo Año & \\
\hline \multirow[t]{2}{*}{$\begin{array}{l}\text { Marianela, Benito Pérez } \\
\text { Galdós }\end{array}$} & $\begin{array}{l}\text { El gato negro, E. A. Poe } \\
\text { El Clis de Sol, Manuel } \\
\text { González Zeledón } \\
\text { La Compuerta } \mathrm{N}^{\circ} 12 \text {, Baldomero Lillo } \\
\text { El Barrilito, Guy de Maupassant } \\
\text { El guardapelo, Carlos Gagini }\end{array}$ & $\begin{array}{l}\text { Las carreras de San Juan, } \\
\text { Manuel de Jesús Jiménez }\end{array}$ \\
\hline & Octavo Año & \\
\hline $\begin{array}{l}\text { La Vorágine, } \\
\text { José Eustaquio Rivera }\end{array}$ & $\begin{array}{l}\text { El Hijo, Horacio Quiroga } \\
\text { La muerte y la brújula, } \\
\text { Jorge Luis Borges }\end{array}$ & $\begin{array}{l}\text { Los Hijos de la Malinche, } \\
\text { Octavio Paz }\end{array}$ \\
\hline
\end{tabular}

De acuerdo con una encuesta hecha a cincuenta estudiantes de noveno año de la Unidad Pedagógica de Cuatro Reinas, ubicada en Tibás, en el primer semestre del año 2005, se constató que un 52\% de los estudiantes afirman que leen los distintos textos asignados. Si se observa el cuadro que aparece más adelante, los textos que más lectores tienen son los cuentos. Indagando con la profesora de español de los grupos, se averiguó que la razón por la que estos cuentos tienen tantos lectores es porque se leen en el aula, en voz alta.

Por otro lado, de las obras de lectura obligatoria, la que más les ha gustado, a estos jóvenes de Cuatro Reinas, son el cuento El clis de sol de Magón y La muerte y la brújula de Jorge Luis Borges. Aunque quienes respondieron que les gustan estos dos textos corresponde a un $32 \%$ de los estudiantes, esto es menos de la mitad de los jóvenes que respondieron a la encuesta. 
Otro aspecto importante de observar son los textos que menos les gustan. Estos corresponden a las dos novelas asignadas: Marianela de Benito Pérez Galdós y La Vorágine de José Eustacio Rivera.
A continuación se presenta el cuadro en el que se resumen las preferencias de los jóvenes, así como el bajo porcentaje de estudiantes que dicen que les agrada leer un texto literario.

\begin{tabular}{|l|c|c|c|c|c|c|}
\hline \multirow{2}{*}{ Obra } & \multicolumn{2}{|c|}{ Leídas } & \multicolumn{2}{c|}{ Le gusta } & \multicolumn{2}{c|}{ No le gusta } \\
\hline El clis de sol & 26 & $52 \%$ & 16 & $32 \%$ & 6 & $12 \%$ \\
\hline La ajorca de oro & 26 & $52 \%$ & 9 & $18 \%$ & 2 & $4 \%$ \\
\hline La compuerta N 12 & 26 & $52 \%$ & 11 & $22 \%$ & 4 & $8 \%$ \\
\hline La muerte y la brújula & 24 & $48 \%$ & 16 & $32 \%$ & 5 & $10 \%$ \\
\hline El barrilito & 24 & $48 \%$ & 7 & $14 \%$ & 4 & $8 \%$ \\
\hline El guardapelo & 23 & $46 \%$ & 7 & $14 \%$ & 5 & $10 \%$ \\
\hline La Vorágine & 22 & $44 \%$ & 7 & $14 \%$ & 24 & $48 \%$ \\
\hline Los hijos de la Malinche & 20 & $4 \%$ & 5 & $10 \%$ & 14 & $28 \%$ \\
\hline El gato negro & 13 & $26 \%$ & 6 & $12 \%$ & 4 & $8 \%$ \\
\hline Marianela & 13 & $26 \%$ & 5 & $10 \%$ & 15 & $30 \%$ \\
\hline
\end{tabular}

Si sumamos los tres aspectos que hemos venido desarrollando en este artículo: una educación en el hogar de tipo puramente audiovisual, una falta de cultura lectora y unos textos literarios obligatorios que los estudiantes consideran desagradables, la lectura se vuelve un acto temeroso y poco agradable para los jóvenes. Esto se comprueba cuando se conversa con ellos sobre la literatura estudiada en el colegio.

¿Qué hacer? Los docentes encargados de impartir Español en la educación secundaria, parecen ser los elegidos por la sociedad y por los medios de comunicación para revertir esa tendencia de aversión a la lectura.

Hay mucho que el profesor y el maestro pueden hacer para interesar a los estudiantes en la lectura, pero para ello deben disponer no solo de textos literarios que agraden e interesen a los alumnos, sino también de métodos y técnicas de análisis agradables e interesantes para muchachos entre trece y diecisiete años.

\section{Marianela y La Vorágine, ¿qué rechazan los estudiantes?}

Analicemos dos casos específicos. En sétimo año se lee Marianela y en octavo La Vorágine. Ambos textos no son del agrado de los adolescentes, los consideran largos y aburridos y con temas alejados de su realidad.

De los cincuenta estudiantes de la Unidad Pedagógica de Cuatro Reinas, Tibás, estas novelas fueron leídas por menos de la mitad de los estudiantes, y de quienes las leyeron, solo un 10\% manifestó que le agradaba Marianela y un $14 \%$ opinó que La Vorágine les gustó

\begin{tabular}{|l|c|c|c|}
\hline Obra & Leída & Le gusta & No le gusta \\
\hline Marianela & $26 \%$ & $10 \%$ & $30 \%$ \\
La Vorágine & $44 \%$ & $14 \%$ & $48 \%$ \\
\hline
\end{tabular}


No hay duda del valor literario y cultural de estas obras dentro de la literatura universal, así como la representatividad de cada uno de esos textos para su época y movimiento literario. Son consideradas grandes obras por representar, reflejar y mostrar un momento histórico determinado, así como por marcar un estilo dentro de la literatura.

Pero ¿qué dicen estos textos a los estudiantes? Pareciera que nada. Ellos no ven la grandeza que poseen ni la llegan a disfrutar. Esto es por dos razones; primero, como ya se mencionó, no han leído casi nada o nada, y segundo, porque al no haber leído antes no tienen parámetros de estilo ni una visión de mundo y experiencia, que les permitan apropiarse del texto y hacerlo suyo a partir de la lectura.

A esta altura de su educación formal no poseen las habilidades lectoras necesarias para disfrutar y analizar un texto de este tipo. Estos muchachos, a quienes se puede calificar como lectores novatos, no tienen los conocimientos acumulados sobre literatura, que les permitan disfrutar los textos.

Por otra parte, como argumentan los estudiantes en muchos momentos, los acontecimientos ahí descritos se alejan de su realidad, intereses y aspiraciones; no les importa lo que ahí se dice, el argumento y los personajes no llegan a atraparlos pues se encuentran lejos de su circunstancias y además, carecen de los conocimientos previos que los ayuden a comprenderlos, disfrutarlos y comentarlos.

Por ejemplo, el tema de amor que se presenta en Marianela, donde Marianela ama a Pablo y la preferencia de este último, por la belleza de su prima sobre la fidelidad y solidaridad de Marianela, son temas de ayer y hoy, pero como se viven actualmente se alejan de cómo los mostró Pérez Galdós. A nuestros muchachos esa problemática no les dice mucho, y en ocasiones les causa extrañeza o risa, aunque en la mayoría de los casos los deja indiferentes.

La estética, los valores y las relaciones ahí mostradas, no son las que ellos conocen, y los jóvenes no tienen la suficiente información ni cultura literaria para trasladar el tema desde el realismo español del siglo XIX a la Costa Rica de principios del siglo XXI. El texto es ajeno, y es al docente a quien pareciera le corresponde darle toda la información al estudiante para que se acerque a él y pueda empezar a interesarlo.

El otro caso antes mencionado, La Vorágine presenta aún más problemas para un lector inexperto. Con solo ojear el léxico empleado en la obra, se puede entender porqué del rechazo ocurre desde la primera página. Es un lenguaje popular, usado en la Colombia del siglo pasado. Ininteligible para costarricenses jóvenes de esta época y este tiempo.

El problema no cesa ahí. Pues bastaría hacer un glosario del léxico, con las palabras desconocidas y su respectivo significado (por cierto, algunos profesores lo han hecho y han llegado a escribir cuatrocientas palabras de difícil comprensión, solo en los primeros capítulos). El problema como se dijo, sigue con la estructura de la historia. Por primera vez se les presenta a estos estudiantes, lectores novatos e inexpertos, una novela con el orden perturbado, que va de atrás para adelante y de adelante para atrás en el tiempo y los acontecimientos, con profusión de historias, personajes $\mathrm{y}$ acciones, que los llevan a un torbellino que los vence, si lograron pasar del primer capítulo.

Y la queja es la misma que se oye cuando en sétimo año leen Marianela, "lo que pasa ahí no nos importa", "no tiene que ver con nosotros", "no lo entendemos porque no sabemos de qué se habla". No saben ni pueden hacer las relaciones con la época actual, no pueden abstraer lo que pasó en aquellos momentos en Colombia y aplicarlo a la historia y al momento que vive Costa Rica y el mundo.

Aquí, nuevamente entraría a jugar un papel importante el docente, quien debería desde ubicarlos en un mapa en la llanura colombiana, hacerlos investigar el 
contexto histórico, económico y social en que fue gestado el texto, hasta elaborar un paralelismo entre la historia del banano en Costa Rica y la del caucho en Colombia.

Las razones que estos estudiantes de la Unidad Pedagógica de Cuatro Reinas, aducen para que nos les gusten estos textos son variadas, pero una de las más señaladas es el aburrimiento que les provoca leer los textos. De los cincuenta estudiantes a los que se les preguntó un 54\% de los jóvenes manifiesta que la lectura de estas dos obras les produce aburrimiento. Otro aspecto que los intimida y aleja del texto es el tamaño de la obra, así lo manifiesta el $38 \%$ de los muchachos.

Como se puede observar en el siguiente cuadro, aparecen otros elementos, además de los antes mencionados que los estudiantes consideran que los alejan de los textos de lectura obligatoria de la secundaria:

\begin{tabular}{|l|c|c|}
\hline ¿Porqué no le gusta & Estudiantes & Porcentaje \\
\hline Aburrido & 27 & $54 \%$ \\
\hline Largo & 19 & $38 \%$ \\
\hline La historia no le interesa & 12 & $24 \%$ \\
\hline El vocabulario es difícil & 10 & $20 \%$ \\
\hline No la entiende & 9 & $18 \%$ \\
\hline No se acerca a la realidad & 1 & $2 \%$ \\
\hline $\begin{array}{l}\text { No se identifica } \\
\text { con los personajes }\end{array}$ & 1 & $2 \%$ \\
\hline Alejado en el tiempo & 1 & $2 \%$ \\
\hline
\end{tabular}

Ante este panorama, cabe preguntarse ¿Porqué estos estudiantes no pueden hacer relaciones y lograr interpretaciones con la lectura de los textos asignados? Por lo mismo que ya se dijo antes. No han leído, sus conocimientos y habilidades lectoras son mínimas, en otras palabras no conocen el código que se necesita para descifrar este tipo de textos.

Ubicándonos en esta situación pareciera ser que la labor del docente de Español, consiste en iniciar el afinamiento de las habilidades lectoras de los jóvenes, entusiasmarlos con la lectura de textos literarios que le sean cercanos, placenteros y agradables, para, más adelante, enfrentarlos a experiencias lectoras más profundas que impliquen análisis textual, interpretación, ubicación en movimiento literario y género a hacer lecturas más lejanas en el tiempo y con visiones de mundo que los adolescentes no conocen.

\section{Un caso que no es típico}

No ando tan equivocada en mis apreciaciones sobre el gusto de los estudiantes por la lectura, basta con entrar a un aula de noveno año y observar con el agrado que reaccionan ante la lectura de Única mirando al mar del costarricense Fernando Contreras.

Este libro si lo leen, cualquier docente de Español lo puede confirmar y los mismos estudiantes lo afirman, a estos últimos no les preocupa la próxima comprobación de lectura, ni el tedioso análisis que se avecina.

Se sienten identificados con el texto, lo sienten cercano, comprensible. Ellos conocen la ubicación real de Río Azul, saben de los problemas del relleno sanitario, ya sea el de San José o el de su comunidad, han vivido en carne propia los problemas de la basura, han visto a los buzos, han arrugado la nariz cuando los ven escarbando en la basura de las calles. Conocen los sitios a los que hace referencia el texto: Puntarenas, la Casa Presidencial. Se pueden identificar con el mundo mostrado porque reconocen en él a su propio mundo.

Se relacionan de tal manera con este texto, que hay alumnos que cuando terminan de leer Única, le aseguran a su profesora que desde ese momento empezarán a dejar un pedazo de pizza en la caja, para que Única u otro buzo se lo encuentre y se lo coma, o un poquito de leche o de cereal. Por supuesto que el docente tiene que ubicarlos y hablarles sobre la diferencia que se da entre la realidad social de la Costa Rica de hoy y la realidad que aparece en 
la ficción, pero estas reacciones ingenuas muestran que el estudiante se identifica con la obra, se siente parte de ella, se reconoce en el texto y puede iniciar con él un incipiente diálogo, es el principio de una comprensión del mundo literario.

Única mirando al mar los motiva, los hace leer, pero otros, como de los que se habló antes o como La muerte y la brújula, de Jorge Luis Borges o Modelo Epistolar del costarricense Aquileo Echeverría, le son indiferentes, lejanos, incomprensibles y muchas veces los desmotiva a seguir ejerciendo el acto de la lectura.

No me había percatado del paso del tiempo y de los cambios sufridos en Costa Rica desde que Aquileo escribió sus Concherias, hasta que una estudiante me dijo que Modelo epistolar estaba escrito en "otro español", pues tenía palabras que no existían y me puso los ejemplos de tequioso, cuadril, pujo, realeras o flato entre otras muchas y que hubo que explicar en ese momento para que el texto adquiriera sentido.

Además, esa conchería toca un tema que es ajeno a la Costa Rica de hoy, un hombre que hace su servicio militar. Este tema es impensable en nuestra Costa Rica. El mundo de Aquileo, es un mundo que desapareció de nuestra realidad y los muchachos no conocen ya ni por referencia, pues sus padres e incluso sus abuelos, no lo conocieron.

Y ni qué hablar de Borges. El cuento La muerte y la brújula es magistral, representativo del estilo de Borges, lleno de "senderos que se bifurcan" y que no conducen a ningún lado más que a la trampa, el engaño y que sirven para distraer al personaje del cuento y al inocente lector, en este caso, los estudiantes de octavo año, que no tienen la pericia y preparación para seguir la línea principal del relato de Borges, a menos que su profesora los guíe paso a paso para desentrañar el misterio ahí presente. Este fue el caso de la docente de Cuatro Reinas, quien afirma que hay que llevarlos de la mano, para que comprendan el texto.
Encima tiene múltiples referencias a la simbología que va desde la hebrea hasta la de los relatos policiales de Edgar Allan Poe. Una profesora, preocupada porque sus alumnos pudieran comprender mejor el relato, elaboró, con ayuda de los estudiantes una lista del léxico del cuento que no comprendían y listaron más de doscientas palabras de difícil comprensión. Con todas estas trabas, es imposible lograr que el estudiante disfrute del cuento y pueda interpretarlo a la luz de sus conocimientos.

Dice Carlos Lomas, profesor de español que se ha dedicado a escribir sobre temas de la enseñanza del español en los colegios, respecto a este tipo de literatura:

“...cuanto más innovador es un texto respecto a las corrientes literarias, tanto más difícil puede resultar su lectura, ya que el alumno no tiene "expectativas" que puedan ayudarle a descifrar el texto" (Lomas. 1999. P. 117).

Los estudiantes de trece y catorce años no están preparados aún para abordar este tipo de literatura. Antes de entrar a leer las grandes obras de la creación universal, o los textos más novedosos en cuanto a tema o estilo, tienen que empezar a disfrutar el texto, a ver en un cuento, en una novela, un objeto de goce y placer, necesitan primero aprender a leer y a disfrutar lo leído.

Recordemos, además que por leer no quiero decir que sea dar significado a una palabra después de otra, sino darle un sentido al texto, a apropiarse de él y sobre todo, disfrutarlo. A disfrutarlo porque se siente retratado en él, se siente parte actuante del texto y porque llega a compartir o a discutir con los pensamientos y vida de los personajes.

No se puede culpar a estos muchachos por detestar Marianela o La Vorágine, se les está abriendo la puerta de la literatura desde un lugar equivocado, desde el lugar del conocimiento avanzado y de la apreciación adulta y no desde la puerta del disfrute y el placer, propio del adolescente 
despreocupado y sobre todo, desconocedor de la literatura y del ejercicio de la apropiación del sentido del texto.

\section{Los caminos que se pueden tomar}

De acuerdo con mi experiencia, existen dos caminos para hacer que el alumno de hoy se acerque a los libros. El primero es el que se está aplicando actualmente. Una selección de obras hecha por expertos en la literatura, donde se escogen determinados textos para que los adolescentes lean obras importantes dentro de la literatura universal, que representen un movimiento específico, una época, un estilo o un género literario particular. Obras casi siempre provenientes de tiempos pasados, con lenguaje propio ya sea de la época o del país y con una narración de hechos importantes pero lejanos en tiempo, espacio, valores y costumbres de los jóvenes de hoy.

El otro camino es enseñar a los estudiantes a leer, a disfrutar los textos, a hacerlos suyos y para buscar un diálogo con el texto. Esto se lograría mediante la escogencia de literatura que presente temas que los atraigan, con los que logren identificarse y que puedan constatar con la realidad que los rodean, acordándonos que la cultura audiovisual de la época ha educado al joven en lo inmediato, lo tangible y lo conocido.

Para lograr este acercamiento, los textos literarios que se escogen tienen que hablarles a los jóvenes, ser divertidos y mostrarles el mundo que viven desde una nueva perspectiva, pero con la que se puedan identificar. Para esto no hay que desechar la calidad literaria o la universalidad de las obras, pero sí hay que pensar en el lector, su edad, su cultura y su ausencia de formación lectora en el hogar. Carlos Lomas lo hace patente cuando dice:

“...en la selección de los textos literarios no deben utilizarse solo criterios estrictamente académicos (en función del prestigio cultural de la obra elegida) sino también, y sobre todo, consideraciones en torno a qué textos pueden facilitar mejor el acercamiento del lector al texto y la identificación de las convenciones y de los indicios textuales que favorecen tanto el contrato comunicativo entre el autor y el lector al que el texto invita, como en consecuencia la comprensión y el disfrute de la obra" (Lomas. 1999. P. 110).

El acercamiento al texto se logra por muchos factores, y cada grupo se acerca desde un lugar determinado. El lugar de acercamiento de los jóvenes se encuentra desde su inexperiencia como lectores y su educación audiovisual y concreta. Por eso, al escoger la literatura que han de leer se deben tener en cuenta estos aspectos. Hay que pensar en que estos posibles lectores son novatos, inexpertos que no poseen las armas necesarias para acercarse y disfrutar del texto literario.

No se puede culpar del todo al estudiante por no leer, la escuela tiene parte de la responsabilidad de ese desinterés, pues al escoger los textos no se piensa en el joven actual que como se ha venido exponiendo tiene sus raíces educativas en esta época del Internet y los vídeo juegos.

Otro problema que se presenta, aunado al tipo de escogimiento de obras que se ha estado haciendo, tiene que ver con el acercamiento que el docente promueve en el aula. En muchas ocasiones el acercamiento se hace mediante pruebas de comprensión de lectura o con análisis dados por los distintos libros de texto.

En muchas ocasiones las pruebas comprensión de lectura se elaboran utilizando preguntas sobre detalles minúsculos del texto, que un muchacho si ha leído, no le han sido significativos y no los puede recordar en el momento de responder la prueba. Preguntas como “¿A quién estaba dedicada la segunda parte del Ingenioso Hidalgo Don Quijote de la Mancha? o ¿Cuándo es el cumpleaños de Marianela?², alejan aún más al estudiante de la lectura pues estos datos ni son relevantes para la comprensión del texto ni lo motivan a seguir leyendo.

Por otro lado, si el docente hace un análisis del texto, muchas veces está 
basado en los dados por los distintos libros de texto que se usan en el aula. Textos como Tiempo de Leer de la Editorial Santillana, Español de Eduvisión u otros que se pueden encontrar, presentan un análisis esquemático, fragmentado y simplista que no abre la puerta a la interpretación ni al disfrute del texto.

En el texto Tiempo de Leer de undécimo año, se analiza El ingenioso hidalgo Don Quijote de la Mancha (II Parte). El análisis que propone se basa en las características generales (género y movimiento literario), el tipo de narrador, la organización secuencial y el código apreciativo. Cada uno de estos temas se explica en dos o tres líneas, como se presenta en el siguiente ejemplo tomado del texto en mención:

\begin{tabular}{|l|l|}
\hline Organización secuencial & Ejemplos \\
\hline $\begin{array}{l}\text { Lineal. Predomina en la } \\
\text { obra, tanto en la primera } \\
\text { como en la segunda parte. }\end{array}$ & $\begin{array}{l}\text { A este tiempo llamaron } \\
\text { a la puerta, y pregun- } \\
\text { tando quién llamaba, } \\
\text { respondió Sancho Panza } \\
\text { que él era; y apenas le } \\
\text { hubo conocido el ama, } \\
\text { cuando corrió a escon- } \\
\text { derse por no verle, tanto } \\
\text { le aborrecía. (II Parte, } \\
\text { cap. IV). }\end{array}$ \\
\hline
\end{tabular}

(Morales. 2006:14).

El análisis de la segunda parte del texto de Don Quijote, se limita en este libro a dos páginas, organizadas y explicadas como se vio en el ejemplo trascrito anteriormente. La explicación es simple, pobre y superficial. Además de ser fragmentada y sin posibilidades de trascender el texto.

Por otro lado, esos libros, en sus análisis encasillan a la obra literaria y proporcionan un único acercamiento, olvidándose que la literatura debe analizarse desde una perspectiva crítica, plural y creativa, tal y como aparece consignado en los Planes de estudio de español del Ministerio de Educación Pública (MEP. 2005:15).
Con este tipo de análisis el estudiante no tiene la oportunidad de dialogar con el texto, de interpretarlo de acuerdo con sus conocimientos, su experiencia que por más limitada e incipiente que sea puede hacerlo Por si este tipo de análisis, cerrado, único y simplista no fuera suficiente, el docente, en el examen parcial, le pregunta sobre el análisis del libro de texto, y una vez más, el estudiante se ve limitado y no puede expresarse, pues se le exige una única respuesta, que aparece en el libro de texto estudiado.

Los expuesto hasta aquí permite formarse una idea del porqué los estudiantes de secundaria no leen, se ha escogido el camino de la tradición, de la imposición. Se ve la literatura como deber y obligación y no como placer. Se olvida de la parte lúdica, de diversión y placer que puede proporcionar cualquier texto literario y se enseña como si nuestros alumnos fueran a convertirse en críticos ortodoxos de literatura o estudiosos acuciosos del tema.

Los docentes y las personas encargadas de escoger los textos de lectura obligatoria olvidaron que el texto literario debe producir placer. Se está presentando el texto literario como una obligación, que hay que leer para contestar preguntas cerradas. Con una única respuesta para obtener una nota final que le permita promover de nivel.

La enseñanza formal debería ser el lugar donde el estudiante se enamore de la literatura, donde la vea como un espacio de placer y creación, y una vez que la vea como algo placentero, iniciarse en la tarea de análisis y crítica, pero siempre desde el lugar de la creatividad, la pluralidad y el placer.

Hasta el momento la escuela no ha logrado convertir a los textos literarios en fuentes de placer, porque escoge textos que no lo motivan a la lectura, que no lo interesan ni lo atrapan. Se han olvidado del joven que llega en estos tiempos a las aulas, rodeado de elementos tecnológico e identificado con intereses propios de su edad que 
no tienen relación con las preocupaciones de Pérez Galdós, Gustavo Adolfo Bécquer o José Luis Borges.

Estos últimos son grandes creadores, han pasado a la historia de la literatura gracias a sus maravillosas obras, pero no logran cautivar a un público desconocedor de la belleza de la literatura y de los intrincados mecanismos para apropiarse del texto y hacerlo suyo porque nadie les ha enseñando a apreciarlo.

\section{Papel del profesor como motivador de la lectura}

De todo lo expuesto hasta el momento pareciera surgir un reto. El docente tiene que llevar al alumno al conocimiento y el disfrute del texto. Dice Roland Barthes que "Leer es encontrar sentidos" (Barthes. 1980:7) y añade Ostria:

“...éste es el desafío al que nos enfrentamos los que nos dedicamos a la enseñanza o al fomento de la lectura: aprender a leer de nuevo los signos de los tiempos." (Ostria:2005).

Con los textos adecuados esta sería una ruta que el profesor debe emprender: hacer que el adolescente le encuentre sentido al texto desde esta época tecnológica y virtual que nos tocó vivir.

El docente debe tomar el papel de mediador que motiva a la lectura. Si se observan los aspectos de la tecnología y su injerencia en la creación de una nueva sociedad donde la lectura no es la esencial, la falta de cooperación del hogar para crear hábitos lectores en los alumnos, los textos de lectura obligatorios que no se ajustan a los intereses de los alumnos; el docente es el llamado a ejercer un papel central en el deseo que pueda surgir en los alumnos por leer.

Sin embargo, en muchas ocasiones el profesor no cumple esta función, como lo afirma la profesora colombiana Lucelly Arroya (1995), cuando afirma
"EL cultivo del gusto por la lectura está invertido en muchos centros educativos, se lee desde una función pragmática. La normatividad específicamente en la tarea evaluativo y el afán por el logro de resultados en el llamado rendimiento escolar, anula toda posibilidad de construcción del ser, toda posibilidad de encontrar respuesta a las propias inquietudes, de estimular la comprensión analítica de cuestionar, de asentir sobre la idea de distintos autores, de gestar la construcción escrita de lo que se piensa y siente" (Arroya:1995. P. 116).

No se aleja de la realidad esta profesora colombiana, actualmente los docentes se preocupan porque el alumno lea para realizar una prueba de comprensión de lectura, con preguntas a veces tan específicas que desilusionan a los pocos que leyeron.

No olvido una pregunta en una comprobación de lectura del texto La loca de Gandoca de Ana Cristina Rossi, donde la profesora pidió a sus alumnos que le respondieran: “¿Cuántos cigarros se fumó el protagonista masculino durante el transcurso de la novela?", o aquella otra que descubrí de Única mirando al mar, “¿De qué estaba hecho el árbol de Navidad que usaron para celebrar Única y sus amigos?, sin olvidar la célebre que se hacía cuando se leía María de Jorge Isaacs: “Cómo se llama el perro de María?

¿En qué ayudan los cigarrillos, el material del árbol de Navidad o Mayo el perro de María, para comprender el texto o buscarle sentidos? La respuesta es obvia, en nada. Con este tipo de preguntas lo único que se consigue es que el estudiante se fije en detalles que casi nunca ayudan a la comprensión del texto ni a su interpretación.

Como se dijo anteriormente una vez realizada la comprobación de lectura, el docente se limita a hacer que sus alumnos lean, resuman o contesten un cuestionario de análisis que aparece en el libro de texto que se usa, para finalmente, preguntar en el examen parcial, sobre alguno de los aspectos resumidos, leídos o contestado en clase. El alumno solo tiene que hacer uso de su buena memoria y reproducir lo que otro dijo sobre el libro. Con este método, yo misma me pregunto ¿para qué leer? 
Hay que observar, como lo dice Mauricio Ostria y Jesús Martín-Barbero que:

Quizá la actual crisis educativa, en lo que dice relación con la lectura, especialmente con la lectura de textos literarios, no tenga tanto que ver con la incorporación de las nuevas tecnologías en sí, cuanto con los profundos cambios que ellas implican y que significan un continuo e inestable proceso de reorganización y reubicación de saberes y sistemas de codificaciones, cuestión, que todavía no terminamos (o no empezamos) a asimilar adecuadamente. Tal proceso implica profundos cambios en los modos de leer, no siempre advertidos por los que se obstinan "en seguir pensando la lectura únicamente como modo de relación con el libro y no con la pluralidad y heterogeneidad de textos y escrituras que hoy circulan" [Martín-Barbero 1993:30-1]. (Ostria:2005. P. 3).

Como dije antes, se sigue proponiendo un acercamiento a la lectura desde una forma tradicional, empleada por los maestros de otras generaciones, cuyos alumnos no tenían el acceso a los nuevos saberes que tienen los jóvenes actuales. Por eso, se puede afirmar que un joven expuesto a las tecnologías que lo rodean todo el día, tendrá que leer diferente, pues posee otros códigos tanto de lectura como de interpretación que no son semejantes a los que usaban los abuelos en los tiempos que no existía ni siquiera la televisión,

"éste es el desafío al que nos enfrentamos los que nos dedicamos a la enseñanza o al fomento de la lectura: aprender a leer de nuevo los signos de los tiempos". (Ostria:2005. P. 4).

Este es el desafío del docente de Español del siglo XXI, aprender a leer y enseñar a leer desde esta época, conociendo los saberes que dominan los jóvenes y proponiéndoles acercamientos a la lectura creativos, plurales y críticos, que les provoquen placer y les amplíen sus capacidades, tanto lúdicas como críticas y analíticas.

Los saberes de este principio del siglo se encuentran en lo tecnológico, en lo visual, en lo auditivo, en lo concreto. El docente necesita recordar constantemente que los adolescentes son capaces de leer, pero leen otros códigos que no son los escritos, por eso, se debe empezar con la enseñanza de las habilidades lectoras de los códigos escritos.

El proceso de enseñanza de la lectura tradicional no acerca al joven al placer de la lectura, más bien este se va perdiendo en ese proceso tedioso, unidireccional y repetitivo en que se ha convertido actualmente la lectura, es un proceso que busca la evaluación sumativa y no el análisis, la discusión, el adentrarse en el texto y llegar a formar un pensamiento propio sobre él, apoyados en los saberes que el adolescente domina y en sus habilidades para leer otros códigos que no son los impresos.

\section{Más que una conclusión... una sugerencia, un deseo}

De acuerdo con las ideas que aparecen en el proyecto Tuning, impulsado por la Comunidad Europea, la enseñanza debe cambiar, porque el mundo, como ya se dijo antes, ha cambiado:

El mundo de nuestros días se caracteriza por sus cambios acelerados. Una serie de factores generales tales como la globalización, el impacto de las tecnologías de la información y comunicación, la administración del conocimiento y la necesidad de patrocinar y gestionar la diversidad hacen necesario un entorno educativo significativamente diferente. (Proyecto Tuning, 2005).

Vivimos en el futuro, somos habitantes de un mundo que Adlus Huxley soñó y que ya está aquí. Nosotros, como docentes tenemos que tomar conciencia de nuestro habitar en un mundo que hace pocas décadas parecía ser solo una ficción alucinada de Huxley.

Solo si el docente se decide habitar este futuro de hoy podrá encontrar caminos con los que podrá ayudar a leer a este joven que vive el presente. Por eso, hay que enseñar a leer de otra forma, una forma donde el conocimiento no esté reñido con el placer del texto, tal y como Roland Barthes (1981) lo definió en la última mitad del siglo XX. 
Esto es lo que opina el francés acerca del placer que le debería provocar el texto al lector:

El placer del texto "Es el que contenta, colma da euforia; proviene de la cultura, no rompe con ella y está ligado a la práctica confortable de la lectura... “

"El placer del texto no es seguro. Nada nos dice que el mismo texto nos gustará por segunda vez, es un placer que fácilmente se disuelve, se disgrega por el humor, el hábito, la circunstancia, es un placer precario" (Barthes:1981. P. 68).

Tal y como se enseña hoy ¿se logra que el estudiante sienta placer? Aunque sea un placer precario, momentáneo y cómodo. Un placer que venga del mismo texto que aunado a la cultura que rodea al joven le permitan olvidarse de todo y sumergirse en el mundo de palabras e ideas que lo transporten, lo diviertan y le permitan ampliar su mundo, su vida.

Este mundo futuro en el que vivimos hoy nos ha abierto las puertas a nuevos conocimientos y nosotros, como docentes de Español tenemos que saber aprovecharlos e incluirlos en las clases de literatura que damos a los jóvenes, Octavio Paz no era ajeno a los cambios del mundo y por eso dice:

"Todos los elementos y formas de expresión que aparecen aislados en la historia de la poesía: el habla y la escritura, el recitado y la caligrafía, la poesía coral y la página iluminada del manuscrito, en suma: la voz, la letra, la imagen visual y el color, coexisten en los modernos medios de comunicación. Pienso claro está, en el cine y en la televisión. Por primera vez en la historia, los poetas y sus intérpretes y colaboradores -músicos, actores, tipógrafos, dibujantes y pintores-disponen de un medio que es, simultáneamente, palabra hablada y signo escrito, imagen sonora y visual, en color o en blanco y negro. Además, en las pantallas del cine o la televisión aparece un elemento completamente nuevo: el movimiento" [Paz 1990:91].

La época nos proporciona múltiples medios para que usemos en las clases de literatura, aprovechémoslo, integrémoslo a la enseñanza de la lectura y hagámosle ver a los estudiantes que la lectura de la literatura es placer, diversión, pensamiento y pluralidad.
Eso sí, hay que partir del hecho que el docente ama la lectura, si no es capaz de divertirse con ella y no le proporciona placer, no será capaz de enseñarles a los estudiantes que la literatura es agradable y un medio de conocer mundos que de otra manera sería imposible explorar.

Joa Loáiciga, profesor de Español de sétimo año del Colegio Luis Dobles Segrega, San José (2205) opina:

"El proceso de motivación es complejo en sus múltiples facetas, ya que intervienen diversos componentes como la actitud del docente, el contexto del estudiante, sus conocimientos previos y sobre todo sus intereses y, tomando en cuenta este último componente, hay que insistir que el sétimo año escolar constituye un módulo de acercamiento al texto, es un año de ambientación literaria, máxime cuando se sabe que el texto no siempre responde a los intereses inmediatos de la adolescencia y que además el alumno deviene de un contexto escolar donde la actividad literaria es prácticamente nula” (Loáciga, 2005).

Para que el adolescente lea no solo hay que enseñarle la habilidad de la lectura de textos impresos, sino que tiene que relacionarlo con su cultura, con esa cultura que lo envuelve y lo llena, y que él vea en ese texto un instrumento de placer y diversión, no un objeto de obligación, notas, cuestionarios y en fin... algo aburrido.

Como dice el profesor del Dobles Segreda, también es necesario tener en cuenta el contexto en que se desarrolla el alumno a quien queremos hacer leer, así como sus conocimientos previos, sus gustos e intereses. A partir de ese conocimiento, el docente tendrá armas que le permitirán acercarse al texto literario desde los intereses de los jóvenes, desde su mundo. Hay que guiarlo a una lectura que lo tome en cuenta, que lo implique y lo haga activo ante el texto, y esto solo es posible si el joven lee desde su realidad, desde su mundo y su vida. Así, poco a poco irá entendiendo que el texto es algo más que notas y obligación y que implica placer, diversión, gozo y vida. 


\section{Notas}

1. El Rincón del Vago es uno de los sitios de Internet más visitados, pues en él se encuentran resúmenes de las obras literarias de lectura obligatoria en colegios de distintos países de habla hispana (Dirección: http://www. rincondelvago.com/)

2. Estos preguntas fueron tomadas de forma literal de dos pruebas cortas de comprensión de lectura de dos estudiantes de sétimo y décimo nivel, de un colegio privado de San José.

\section{Referencias bibliográficas}

Arroya, Lucelly. (1995). "La lectura como experiencia de aprendizaje en la práctica educativa" En: Revista de la Universidad de Caldas. Colombia. Julio-diciembre.

Barthes, Roland. (1980). S/Z, México, Siglo XXI.

Barhes, Roland. (1981). El placer del texto. México, Siglo XXI.

Borges, Jorge Luis. (1998). "La poesía" En: Siete Noches. México, Fondo de Cultura Económica.

Calvo, Blanca. (1999). "Con cien números por banda" En: Educación y Biblioteca. Año 11, $\mathrm{N}^{\circ}$ 100, Madrid, abril de 1999 Tomado de:

http://www.clubdelibros.com/

farticulo12.htm (Artículo extraído, con autorización de los editores, del número especial).

Garrido, Felipe. (2005). Fuera del diccionario Rescatado de:

http://cvc.cervantes.es/obref/

congresos/zacatecas/libro/ comunicaciones/garrido.htm 13 de Abril de 2005.
Loáiciga, Joao. (2005). "La motivación hacia los textos poéticos de Béquer". Trabajo de Investigación, curso FD-0550 Seminario de la enseñanza del Castellano y la Literatura. Universidad de Costa Rica.

Lomas, Carlos. (1999). Cómo enseñar a hacer cosas con las palabras. Volumen II. Barcelona, Paidós.

Martín Barbero, Jesús. (1993). "Nuevos modos de leer", En: Revista de Crítica Cultural (7). 19-23.

Martín Barbero, Jesús. (2002) "Jóvenes: comunicación e identidad". En: Pensar Iberoamericana, Revista de Cultura. Número 0. Febrero 2002 Rescatada de http://www.campus-oei.org/ cultura/barbero.htm el 12 de abril.

Méndez, Silvia. (2000). "La mediación docente en la comprensión de lectura de textos literarios" En: Revista Educación. 24(1).

Ministerio de Educación Pública. (2005). Plan de estudio de Español. MEP, San José.

Paz, Octavio. (1990). Hombres en su siglo $y$ otros ensayos. Barcelona, Seix Barral.

Penac, Daniel. (1992). Como una novela. Barcelona, Grupo Editorial Norma.

Proyecto Tuning. (2005). Rescatado de: http://www.relint.deusto.es/ TuningProject/index.htm el 5 de mayo.

Ostria, Mauricio. (2005). "Enseñanza de la literatura en los tiempos que corren". Rescatado de. http://www.uchile.cl/facultades/ filosofia/publicaciones/cyber/cyber14/ tx26mostria.html el 15 de Marzo. 
Real Academia Española. (2001). Diccionario de la lengua española.

Vigésima segunda edición. Madrid, Espa. 